\title{
O Planeamento no Contexto de uma Sociologia da Acção As Rearticulações Teoria-Prática no Campo da Sociologia e Planeamento
}

Isabel Guerra *

\begin{abstract}
$\mathrm{R}$ da necessidade de ancorar a metodologia de planeamento, tal como a defino, no campo da sociologia entendendo-a como "uma forma de construção da acção colectiva, no contexto da estratégia de actores e com vista à consensualização de um futuro desejável". O modelo conceptual desta discussão está no esquema que se apresenta a seguir e aborda várias dimensões problemáticas das ciências sociais. Em primeiro lugar, as dimensões heurísticas articuladas com a relação entre teoria e empiria que tradicionalmente opuseram uma "sociologia de terreno" a uma "sociologia abstracta" e que está na origem da produção de conceitos, pressupostos e metodologias diferentes que estão hoje disponíveis para a acção do profissional. Em segundo lugar, as dimensões teóricas, que retomam os paradigmas que procuram novos modelos explicativos que melhor trabalham as formas de acção colectiva e, finalmente, uma dimensão metodológica ligada à sociologia da intervenção.
\end{abstract}

Palavras-Chave: planeamento; acçäo colectiva; paradigmas sociológicos.

\section{Introdução}

O objectivo desta reflexão é fundamentar o planeamento no âmbito das ciências sociais e mais especificamente no contexto de uma sociologia da acção. Este objecto decorre da necessidade de ancorar a metodologia de planeamento, tal como a defino, no campo da sociologia entendendo-a como "uma forma de construção da acção colectiva, no contexto da estratégia de actores e com vista à consensualização de um futuro desejável".

O modelo conceptual desta discussão está no esquema que se apresenta a seguir e aborda várias dimensões problemáticas das ciências sociais. Em primeiro lugar, as dimensões heurísticas articuladas com a relação entre teoria e empiria que tradicionalmente opuseram uma "sociologia de terreno" a uma "sociologia abstracta" e que está na origem da produção de conceitos, pressupostos e metodologias diferentes que estão hoje disponíveis para a acção do profissional. Em segundo lugar, as dimensões teóricas, que retomam os paradigmas que procuram novos modelos explicativos que melhor trabalham as formas de acção colectiva e, finalmente, ma dimensão metodológica ligada à sociologia da intervenção.

\footnotetext{
* Professora Associada de Sociologia do ISCTE. Investigadora-Coordenadora do CET. Contacto: isabel.guerra@iscte.pt
} 


\section{A história do desenvolvimento teórico e metodológica da relação entre Teoria e Acção}

Figura 1 - Rearticulações entre Conhecimento e Acção no Campo da Teoria Sociológica

Pode-se enquadrar a discussão do planeamento, no âmbito da modernidade tardia apoiando-nos em Giddens e U. Beck e chamando à colação os autores que, não se reivindicando necessariamente de uma sociologia de intervenção, reequacionaram as novas relações entre Actores e Sistemas e ensaiaram modelos de intervenção face à mudança social.

\section{Complexidade crescente e procura de novas formas de pensar e de agir}

A complexidade crescente das formas de organização social, a pulverização dos interesses e corporações, a multiculturalidade contraditória dos modos de vida aliada à fragmentação e divisão crescente dos poderes decisórios do estado, transforma profundamente as formas de acção colectiva. Para além do aumento da complexidade do mercado e da sociedade civil, assiste-se a um processo de divisão, multiplicação e difusão das instâncias políticas que, transformando as regras de gestão autoritárias de outrora, tentam administrar a complexidade por meio de decisões, de escolhas, de políticas, capazes de reduzir a incerteza dos sistemas que mudam rapidamente, o que afecta de forma pouco controlável a vida dos cidadãos e a organização das sociedades

Estes processos estão ligados à complexidade crescente da sociedade e à necessidade de fazer frente a um ambiente mutável mas também e muito especialmente, à necessidade de garantir equilíbrios no interior de sistemas, sujeitos a contínuas mudanças e de grande instabilidade e, em larga medida, de "alto risco" (Giddens, Beck).

As transformações que decorrem desta "sociedade de alto risco" são inúmeras e de entre elas, como escreve Melucci "as sociedades complexas de alta densidade de informação requerem uma crescente autonomia dos elementos que as compõem: indivíduos e grupos devem funcionar como terminais confiáveis e capazes de auto-regulação $\mathrm{e}$, por isso, estimulados a desenvolver habilidades formais de aprendizagem e de acção" (Melucci, 2001: 27). 
A diferenciação dos sistemas e subsistemas sociais, não detendo todos a mesma importância e estando sujeitos a conflitualidades várias impõem a necessidade de novos equilíbrios face a conflitos que se desenvolvem nas diferentes áreas do sistema com fortes pressões nas problemáticas mais centrais quer ao nível da produção e distribuição dos bens e serviços quer nos níveis simbólicos mais estruturantes.

As relações políticas tornaram-se cada vez mais importantes e os agentes públicos introduzem sistemas de intercâmbio de informações, de negociações, que, através do confronto e da mediação de interesses produzem decisões onde anteriormente funcionavam mecanismos autoritários de normas e de poder. De alguma forma, se poderá afirmar que a inovação deste inicio do século, é a interacção e cooperação programadas com vista a atingir objectivos concertados. De facto, as políticas públicas são entendidas, em larga medida, como "sistemas de cooperação" em matéria de acção pública.

A crescente participação dos actores económicos e sociais nas políticas de desenvolvimento advém de uma certa concepção de gestão da esfera pública que apela à participação dos actores e ao reconhecimento de que cada projecto de mudança social engendra energias positivas para a mudança nos actores envolvidos. Esta definição, transforma a vida social numa multiplicidade de ecossistemas nos quais coexistem em rede todos os que participam no seu desenvolvimento mesmo que ainda fique por clarificar os meios e as modalidades de conectar as diferentes redes e, mais particularmente, as que permitem associar os actores económicos e sociais. O trabalho com os actores, visando o aumento de reflexividade sobre a sua própria acção e interesses, bem como a capacidade de enquadrar os interesses dos outros tem vindo a ser aprofundado por vários sociólogos de nomeada a partir de interrogações, intenções e formas de fazer muito diferentes.

O objecto utópico do planeamento é encontrar a chave da mudança social e, através dela, reduzir as incertezas sociais. Daqui as tentativas, nestes últimos 50 anos, de encontrar um conjunto de teorias e práticas de intervenção sociológica que produzam os utensílios conceptuais e metodológicos que o apoiem na sua missão. Não que a sociologia seja uma ciência de aplicação e possa comprometer-se em recomendações de carácter normativo, prescritivo e ainda menos coercivo. Mas ela é parte integrante de um espaço público que procura formas de viver em conjunto e que frequentemente coloca os sociólogos, nomeadamente os de planeamento, como mediadores na construção da acção colectiva em contextos de grande complexidade e contradição de relações sociais.

Noutro artigo ${ }^{1}$ desenvolvemos os postulados teóricos e epistemológicos que, estando no centro do equacionar do planeamento em ciências sociais, decorrem dessa revisão bibliográfica: o processo de invidualização quer permite o "retorno do actor"; uma determinada concepção da mudança social e do papel do sociólogo.

\section{A revisão das teorias da acção colectiva}

Diga-se então que a evolução da sustentação teórica dos conceitos de planeamento e de "metodologia de projecto" do ponto de vista sociológico, só têm sentido quando orientada para a actividade colectiva e deste facto emerge a necessidade de revisão dos paradigmas preocupados com a forma como se constrói a da acção colectiva .

A chamada de atenção para a acção colectiva é uma reorientação dos olhares face à orientação da sociologia dominante, pelo menos em Portugal. A sociologia sempre esteve mais interessada em aprofundar as formas como a sociedade se reproduz do que as formas como a sociedade se produz a si própria. Ora, as formas de construção da sociedade sobre si própria (a famosa reflexividade) é o objecto central do planeamento.

Talvez nasça aqui este fascínio do planeamento, porque não se trabalha com problemas teóricos ou empíricos, trabalha-se com a auto-produção social, isto é, com capacidade da sociedade se equacionar e agir face a si própria: simultaneamente, a acção e o seu sentido, no contexto das relações sociais.

O quadro referencial do planeamento apela assim à compreensão das transformações da modernidade e à releitura das tradições sociológi-

${ }^{1}$ Cf. Guerra, 2003. 
cas que sempre estiveram, de forma assaz dicotómica, estruturadas entre uma sociologia mais sistémica e funcional e uma sociologias mais estratégica e compreensiva e que hoje procuram alianças profundas e duradouras.

\section{Os cinco paradigmas do equacionar a acção colectiva}

O que nos interessa é identificar os ingredientes desta discussão na tradição sociológica e trazê-los para a actualidade, identificando os pressupostos teóricos e metodológicos que permitem hoje ancorar a reflexão e acção face a sistemas sociais complexos e instáveis sujeitos à normal conflitualidade social.

A acção colectiva é um processo que supõe a participação dos actores que, por definição, têm interesses divergentes não tendo assim aparentemente qualquer razão para ter o mesmo discurso ou os mesmos objectivos. Deveremos perguntar o que faz agir os actores? Porque razão se associam em projectos comuns face a interesses que não são directamente os seus? Como é possível a cada um dos participantes reconhecer numa acção colectiva os seus interesses particulares? Como se formam interesses colectivos? Quem ganha e quem perde nesse processo? Quem protagoniza que interesses e com que valores? Ou ainda, como interroga Bratosin (2001), os que não marcham com o mesmo passo, como encontram a capacidade de marchar com o mesmo coração?

A revisão da bibliografia permite identificar 5 modelos - de desigual aprofundamento e importância para o planeamento - como teorias explicativas das formas de construção da acção colectiva. São eles: as teorias do comportamento colectivo, a teoria da mobilização dos recursos, a frame theory, teoria dos novos movimentos sociais, teoria da democracia participativa ${ }^{2}$. Todas elas contribuem para um certo entendimento do planeamento e da acção colectiva.

Está no prelo um livro da autora deste artigo onde se desenvolvem estes "paradigmas". 


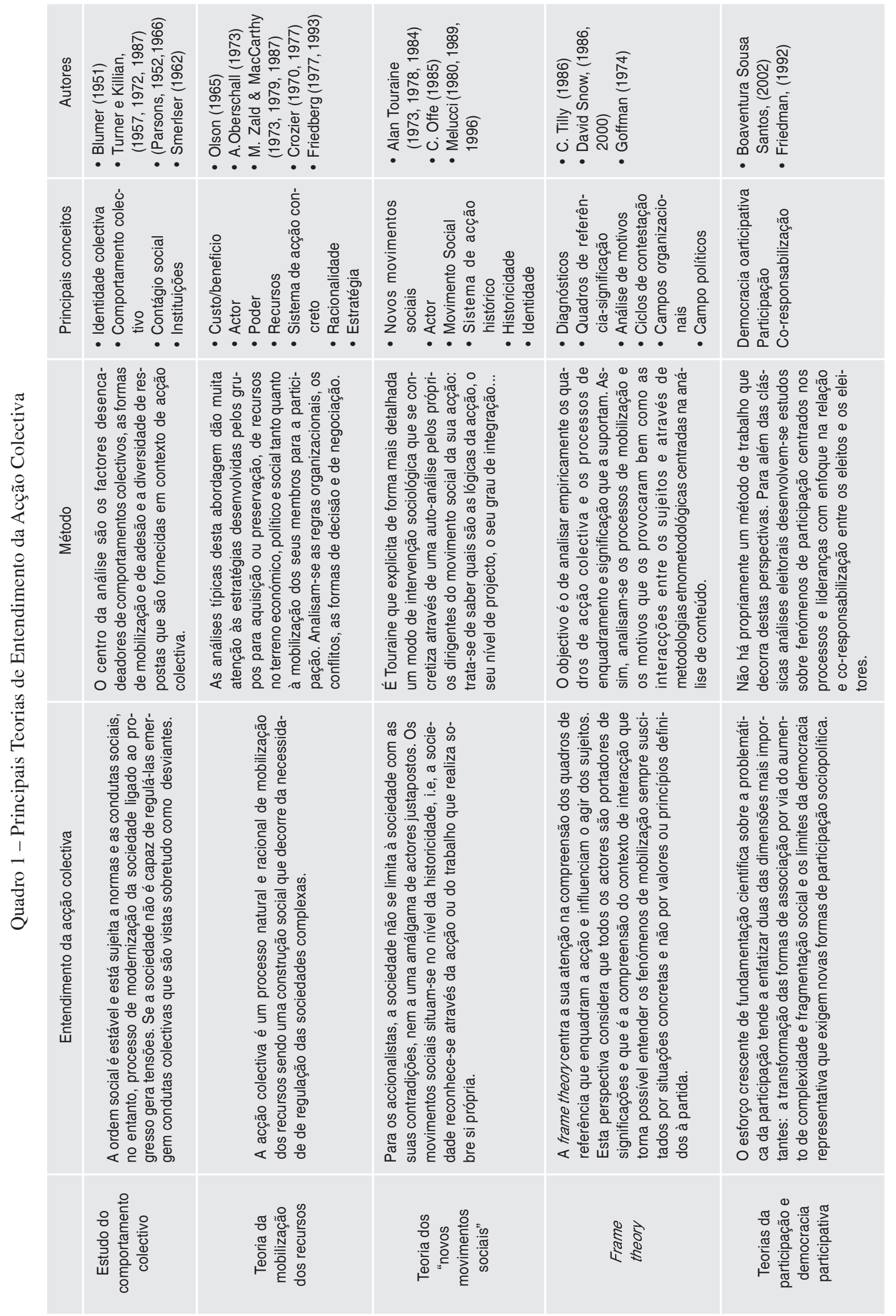




\section{As teorias do comportamento colectivo, ou como a mudança é mal encarada}

As teorias do comportamento colectivo têm um cariz funcionalista e são marcadas por uma visão psicossociológica e microssociológica da acção colectiva enquadrando uma grande divergência de factores explicativos das formas de associação e de mobilização. Sendo uma das "correntes" mais antigas, e com significativa evolução ao longo do tempo, tem como referências centrais alguns sociólogos de nomeada tal como Tarde e Le Bon, mas estas teorias tiveram sempre um grande suporte na escola de Chicago através de Park e mais tarde de Blumer. Estes autores propõem uma metodologia de análise dos movimentos sociais clássica na altura: há um acontecimento desencadeador que provoca agitação na multidão, por processos miméticos essa excitação colectiva é projectada em direcção a uma fonte de atenção. Finalmente, a estimulação das pulsões por contacto é canalizada para uma coordenação das acções que se orientam para um fim colectivo. Os primeiros autores que se interessam pela psicologia da multidão recorreram ao conceito de "imitação" e de "contágio mental ou moral" e de "sugestão". Os comportamentos colectivos são explicados por "contágio", por "imitação", ou por "assimilação".

Com o decorrer dos anos os fundamentos sociológicos do estudo do comportamento colectivo (nomeadamente de Tarde e Le Bon) vão sendo aprofundados e aprofundam-se os determinantes estruturais da acção colectiva emergindo conceitos mais sofisticados, e passa-se da concepção da "irracionalidade" dos comportamentos da multidão ao reconhecimento da influência da cultura nas formas de mobilização (nomeadamente sobre a influência de Blumer e Turner, etc.).

As críticas mais frequentes às teorias do comportamento colectivo são sintetizadas por Fillieule e Péchu (2003) e podem organizar-se em 4 grupos: i) a predominância de uma explicação psicológica que confunde e distingue mal a relação entre as determinantes individuais e colectivas da acção, com sobrevalorização das determinantes individuais e das consequências subjectivas mais do que as determinantes objectivas da acção; ii) a recusa permanente da discussão da dimensão políti- ca, que emerge sempre reduzida às determinantes interindividuais mesmo quando provoca estruturas colectivas com claras orientações críticas; iii) ambiguidade na concepção do actor que parece mobilizado por interesses pouco racionalizados mesmo quando se lhe reconhece um comportamento estratégico; iv) os movimentos sociais são sempre considerados fenómenos excepcionais, que excedem os quadros do jogo social, sintomas de situações de crise, fortemente opostos às formas legítimas de participação democrática. $\mathrm{O}$ pressuposto ideológico é o de que os canais institucionais podem contribuir para um funcionamento democrático ideal.

A explicação do comportamento colectivo através das disfunções sociais ou frustrações psíquicas numa sociedade de massas vai cair em desuso, e do ponto de vista do nosso objecto, são pouco interessantes dado o estatuto de marginalidade que dão às formas de organização colectiva.

\section{A teoria da mobilização dos recursos e a crença na racionalidade do comportamento humano}

A teoria da mobilização dos recursos (TRM), cuja sede institucional foi a universidade de Michigan, e os novos promotores são, nos EUA, A. Oberschall $(1973,1993)$ ou M. Zald \& J. M. McCarthy $(1979,1987)$ e, na Europa, Crozier e Friedberg (1977), impõe-se como paradigma nos anos 70 .

Ao contrário das correntes do comportamento colectivo, as TMR acentuam duas questões básicas bem diferentes. Não há lugar para uma concepção "explosiva" ou espontânea da acção colectiva já que a mobilização é doravante concebida como o resultado de um trabalho de organização, de construção e de captação de recursos materiais e humanos realizado pelos actores sociais que se comprometem face a objectivos conflituais (ou não). Em segundo lugar, a acção colectiva não emerge apenas numa lógica esporádica, espontânea mas também, e sobretudo, como uma acção institucionalizada.

São geralmente apresentadas três linhas de desenvolvimento das TMR que, de algum modo, correspondem também a uma evolução no tempo deste paradigma de entendimento da acção colecti- 
va: a "teoria dos jogos" assente na identificação das condições de cooperação ou de conflito; a teoria da acção colectiva de Olson; e a "abordagem estratégica" de Crozier e Friedberg.

A temática comum que une as diferentes linhas de pensamento e de investigação é a consideração da acção colectiva como ideologicamente legítima resultando de comportamentos voluntários e intencionais. De repente, o objecto de estudo desloca-se passando do estudo dos movimentos de multidão para movimentos colectivos e outros movimentos organizados.

O centro da análise é assim a "acção organizada", a coerência das decisões e as interdependências complexas entre poderes. A acção organizada é concebida como resultado da "racionalidade limitada" dos actores e é um forma de acção colectiva abrindo-se as pistas de análise em torno das formas de mobilização e de acção.

\section{A teoria dos novos movimentos sociais: da excepção da transgressão à procura de novos sentido do devir colectivo}

A perspectiva de análise da acção colectiva que é dominante na Europa, é identificada sob o nome de "teoria dos novos movimentos sociais" (NMS) e constituiu-se em torno de Touraine em França, A. Pizzorno e Melucci em Itália, J. Habermas e C. Offe na Alemanha. Os autores subscritores do "paradigma" dos NMS, aderindo mais ou menos às teses de Bell sobre a sociedade pós-industrial ou pós-materialista de Inglehart, analisam os fenómenos de mobilização colectiva no quadro do desaparecimento da classe operária como actor central da historicidade e a emergência de uma nova classe tecnocrática.

Os NMS ${ }^{3}$ são entendidos como lugar de produção de novas identidades e valores sociais, criadores de espaços de reconhecimento e de representação, inventores de espaços de autonomia e de experimentação cívica e existencial. Criticando a teoria da mobilização dos recursos pelo seu centramento numa explicação fundamentada na racionalidade estratégica individual e pelo esbatimento das dimensões políticas da acção colectiva, a teoria dos NMS vai defender uma análise dos processos a partir dos quais os actores gerem solidariedades e identidades colectivas. Mas estas posturas críticas face à teoria da mobilização dos recursos mostram um cariz muito diferente nos investigadores dos vários países. Os investigadores europeus - sobretudo alemães ${ }^{4}$ - são os primeiros, talvez por razões culturais, a colocar estas questões no início dos anos 70.

A sociologia da acção assume como ponto de partida não a estrutura da sociedade como força de integração mas o sujeito como Actor na produção dessa sociedade. Para os accionalistas, a sociedade não é nem estruturada por forças externas nem é o resultado justaposto de lógicas individuais de actores. Ela encontra a sua lógica própria através das redes de relações que se estabelecem através dos sistemas de acção e de relações entre actores. Os movimentos sociais constituem eles próprios sistemas de acção no interior de um campo sistémico problemático (Melucci, 1985).

Os movimentos sociais situam-se ao nível da historicidade, isto é, a sociedade reconhece - se através da acção ou do trabalho que realiza sobre si própria procurando novos sentidos e identidades que se traduzem em oposições e desvendamento de conflitos e de opções face ao futuro social. Assim, a análise sociológica deve ultrapassar o entendimento de meros fenómenos de reprodução social e procurar atingir o significado profundo da produção da sociedade em si mesma.

Para o nosso interesse sobre as formas de construção da acção colectiva esta é a corrente com maior densidade teórica pois que ensaia uma teoria geral da vida social. A densidade do conceito de "actores" é aqui bem diferente das apresentadas anteriormente e, em larga medida, este aspecto está no centro das interrogações sobre a acção colectiva nomeadamente nos domínios mais enfatizados por esta corrente, a saber, a relação entre os Actores e o Sistema Social. No coração do paradigma dos novos movimentos sociais está uma essencial compreensão do sujeito, mas também das

\footnotetext{
3 Melucci identifica como formas novas de mobilização, o feminismo, o consumismo, os movimentos regionalistas, o ecologismo, as lutas operárias, as contra-culturas juvenis, os movimentos anti-institucionais, as lutas operárias, etc.

4 O conceito de "novos movimentos sociais" tem origem na Alemanha dessa altura. Os americanos continuaram fiéis aos estudos dos quadros de referencia ambientais (organização dos movimentos, repertórios e violências de massa).
} 
dinâmicas societais como fenómenos de transformação cultural da historicidade.

\section{A teoria dos quadros de referência (frame theory) e a crença na construção experiencial dos modelos condutores da acção}

A teoria dos quadros de referência frame theory) é um paradigma não-europeu que contribui para as teorias da acção colectiva. A sua importância advêm sobretudo de duas ordens de razão. Em primeiro lugar, o seu centramento na compreensão dos quadros de referência que enquadram a acção e influenciam o agir dos sujeitos, isto é, as formas de construção social da realidade do mundo, dos problemas dos outros e as representações e valores que influenciam o pensamento e a acção dos actores. Em segundo lugar, o forte pendor crítico - e assaz cínico - que lhe advém da defesa de que, na maioria dos processos participativos, esses quadros de referência substituem a acção concreta através da confusão entre pensamento e acção.

De facto, nas duas últimas décadas, a renovação das teorias da acção colectiva sob a designação da frame perspective contribuiu para realçar os processos cognitivos e normativos nas dinâmicas de mobilização colectiva. Lançada por David Snow e os seus estudantes da Universidade do Texas no início dos anos 80 (Snow et al., 1986) a análise dos quadros conhece um êxito exponencial na literatura dos anos 80, sobretudo nos EUA. Goffman é um dos autores mais citados por este paradigma de compreensão da acção colectiva que se alimenta das contradições e insuficiências da teoria da mobilização dos recursos e explora uma via alternativa apoiando-se na aparelhagem conceptual da escola de Chicago.

Esta perspectiva de entendimento da acção colectiva considera que, na acção social, todos os actores são portadores de significações e que é a compreensão do contexto de interacção que torna possível entender os fenómenos de mobilização, sempre suscitados por situações concretas e não por valores ou princípios definidos à partida. Assim, a frame perspective, tal como é desenvolvida no domínio dos movimentos sociais (Benford, 1997; Benford e Snow, 2000; entre outros), focaliza a sua atenção no "trabalho de significação" através do qual os militantes e outros actores sociais se comprometem.

Contrastando com abordagem tradicional de movimento social como portador de crenças e de significações preexistentes, classicamente contextualizadas em termos de ideologia, esta perspectiva apreende os "actores significativos" (signifiants-signifying agents) mobilizados nas actividades de produção, de manutenção e de reprodução do sentido das organizações populares. Muito curiosamente, identifica todos os actores, nomeadamente os que se opõem aos movimentos sociais, as elites e os meios de comunicação, quer dizer o conjunto de actores ligados aos interesses, aos objectivos e aos desafios que relevam da organização de um movimento social. Tendo em conta todos os implicados (oponentes, participantes ou simpatizantes) analisam-se e confrontam-se argumentos, lógicas de acção e significados. Este trabalho que já foi apelidado de "política da significação" (politics of signification) "enquadra" (e daqui o nome de teoria de enquadramento) o trabalho de significação que é uma das actividades que os aderentes e os dirigentes dos movimentos colectivos fazem de forma contínua.

A questão central é a de saber como analisar empiricamente os quadros de acção colectiva e os processos de enquadramento. A resposta depende da problemática que interessa ao investigador pois os ângulos de abordagem são muito diversificados: pode interessar a ligação entre o desenvolvimento e os quadros de acção colectiva ou os seus efeitos sobre os vários movimentos sociais, etc.

Cefai (2001) propõe um diagnóstico detalhado dos contributos e dos limites das análises dos quadros. Segundo o autor, a principal dificuldade reside no facto de que o "trabalho de significação" só é visto numa perspectiva estratégica menos relacionada com o Goffman da Frame Analysis e mais perto do Goffman da Strategic Interaction. Para Cefai a frame theory está mais próxima da corrente da mobilização dos recursos do que parece. Os quadros de referência parecem ser mais recursos simbólicos accionados pelos líderes dos movimentos numa lógica de organização dos meios para atingir os fins.

Esta concepção instrumental não faz decrescer o interesse sociológico pelas interpretações e sentido subjectivo dos actores nas suas mobiliza- 
ções. Uma dimensão positiva desta abordagem reside no desenvolvimento de metodologias de análise qualitativa ligadas a estas perspectivas de trabalho: narrativas históricas, análises de conteúdo, produção de "grelhas" de análise etc.

Mas as críticas consideram, apesar de tudo, que estamos numa análise estática e de sobrevalorização das dimensões ideológicas que qualificam os quadros de referência sem ter em conta a sua transformação ao longo do tempo, usando demasiado material escrito e jornalístico ou discursivo e desprezando objectos centrais como a análise das organizações.

\section{A teoria do avanço da democracia e da crise de legitimidade: à procura de outras formas de decisão sobre a vida quotidiana}

Esta última "corrente", não vai retomar apenas a teoria sociológica mas tem um grande desenvolvimento na ciência política emergindo de forma transversal nos discursos das várias disciplinas que se confrontam com a problemática da mobilização dos actores ou da "participação" da população. É uma problemática que emerge com uma grande diversidade de vocabulário de origem disciplinar e de épocas diferentes o que torna tudo um pouco mais confuso. Mas a origem da maior confusão e, sobretudo, a sua imersão em dimensões ideológicas mais do que científicas advêm da falta de cuidado epistemológico e teórico na utilização de conceitos produzidos para a intervenção e que não têm, pelo menos de forma clara, fundamentação problemática expressa sendo utilizados no campo científico 5 .

O esforço crescente de fundamentação científica sobre a problemática da participação tende a enfatizar duas das dimensões mais importantes. É, por um lado, a transformação das formas de associação por via do aumento de complexidade e fragmentação social e, por outro lado, uma problemática associada à anterior que discute os limites da democracia representativa e a defesa de novas formas de participação sociopolítica.

Como vem defendendo Boaventura Sousa Santos, a renovação da teoria democrática assenta, antes de mais numa articulação entre democracia representativa e democracia participativa. Para que tal articulação seja possível é, contudo, necessário que o campo do político seja radicalmente redefinido e ampliado, re-politizando as práticas sociais e descobrindo novos campos políticos de intervenção; desvendando novas formas de opressão e de dominação e novas oportunidades para o exercício de novas formas de democracia e cidadania.

A democracia deste ponto de vista, significa considerar que o povo organizado em comunidades políticas constitui a fonte última do poder soberano sobre os espaços de vida que, na era moderna, constituem territórios delimitados por fronteiras. Como "órgão executivo" da comunidade política, o estado é soberano sobre o seu próprio território apenas por extensão da soberania do povo. Em todas as suas acções está obrigado a prestar contas à comunidade. A pertença responsável a uma comunidade política requer a transformação do poder social em poder político (Friedman, 1996).

Assim, o conceito de cidadania está, também ligado de perto ao modelo de pobreza o (dis) empowerment. As pessoas disempowered, especialmente as que vivem abaixo do limiar de pobreza embora não apenas estas porque a exclusão pode assentar também noutros motivos, tais como o racismo, o sexismo - não têm o necessário poder social para exercer significativamente direitos políticos.

A reivindicação é a de que, na sua forma mais simples, a cidadania é um conjunto de direitos e de obrigações que envolvem todos os membros virtuais de uma comunidade política, sem olhar a género, idade, etnicidade, níveis de educação, religião ou qualquer outro critério que possa ser utilizado para restringir uma pertença responsável e excluir cidadãos do exercício sem barreiras de direitos políticos e deveres cívicos.

É Boaventura Sousa Santos (2003) que defende que a democracia representativa constituiu até agora o máximo de consciência política possível do capitalismo mas que esse máximo não é uma quantidade fixa, é uma relação social. A complementação ou o aprofundamento da democracia representativa através de outras formas mais complexas de democracia pode conduzir ao aumento

\footnotetext{
Não se critica essa produção de conceitos para a intervenção sociopolítica mas no campo científico esses conceitos devem ser sujeitos à critica epistemológica e teórica sob pena de se tornarem conceitos de senso comum, integrando sentidos pouco controlados.
} 
do máximo de consciência possível, caso em que o capitalismo encontrará um modo de convivência com a nova configuração democrática, ou pode conduzir, perante a rigidificação desse máximo, a uma ruptura ou, melhor, a uma sucessão histórica de micro-rupturas que apontem para uma ordem social pós-capitalista. Não é possível determinar qual será o resultado mais provável. A transformação social ocorre sem teleologia nem garantia. É esta indeterminação que faz o futuro ser futuro, mas a renovação da teoria democrática assenta, antes de mais na formulação de critérios de participação política que não confinem esta ao acto de votar. Implica, pois uma articulação entre democracia representativa e democracia participativa. Para que tal articulação seja possível é, contudo, necessário que o campo do político seja radicalmente redefinido e ampliado. A teoria política liberal transformou o político numa dimensão sectorizada e especializada da prática social - e confinou-o ao Estado. Do mesmo modo, todas as outras dimensões da prática social foram despolitizadas e, com isso, mantidas imunes ao exercício da cidadania.

Nesse sentido seria necessário renovar a teoria democrática, repolitzar as práticas sociais e descobrir novos campo de contradições sociais desocultando as novas formas de opressão e de dominação e novas oportunidades para o exercício de novas formas de democracia e cidadania.

Assim, um objectivo último da democracia participativa seria o de politizar a vida quotidiana, elucidando as formas de poder que se ocultam nas interacções sociais através da crítica às formas de dominação e desigualdade, alargando as forças emancipadores e fomentadoras da equidade e justiça social.

Esta "pedagogia da emancipação colectiva" está longe do discurso ideológico e confuso de defesa das formas de participação centrando-se nos processos, objectivos e resultados das formas de acção colectiva.

\section{A diversidade no entendimento da Acção Colectiva em Sociologia}

Os vários paradigmas da acção colectiva respondem de diversas formas a estas questões. Des- de o utilitarismo pragmático de Olson, à historicidade reflexiva de Touraine passando à força construtivista da frame theory, as respostas são tudo menos óbvias e o questionamento está em aberto até pela deficiência de pesquisas no domínio das formas de construção da acção colectiva. De facto, o aprofundamento das motivações para a acção colectiva poderá renovar o pensamento sobre as políticas públicas e ultrapassar a análise das relações entre o Estado e as colectividades em termos de dependência e autonomia, introduzindo as complexas noções e processos da cooperação e da negociação.

Até lá é preciso ir avançando nas pesquisas e reconstituir o "filme", quer dizer, analisar as decisões colectivas na sua dinâmica interna, em função de uma série de propriedades mutáveis das interacções que variam em função das situações concretas. A lógica de um processo de acção colectiva, só poderá ser totalmente inteligível $a$ posteriori, a partir de uma análise histórica, pois a maioria das decisões colectivas são factores dinâmicos e processuais que decorrem em circunstâncias concretas em função da percepção de um ambiente de um "sistema de acção concreto".

A maioria dos autores defendem uma abordagem interaccionista do poder para mostrar que a formação de acordos entre as pessoas passa pela construção de representações sociais comuns. No contexto dessa sociologia interaccionista que parte do pressuposto que há vários factores que influenciam os processos de construção da acção colectiva ${ }^{6}$, a construção teórica actual recupera elementos da frame theory defendendo que a formação de acordos não se faz mecanicamente, nem ao acaso, mas em referência a um pequeno número de representações e de interesses que orientam as condutas dos actores. Defende-se, à luz da abordagem estratégica de Crozier, ou da perspectiva clínica de Dubar que qualquer pessoa tem capacidade para interpretar as mudanças sociais (dimensão cognitiva), para enunciar os valores que devem assegurar o respeito pela vida colectiva (dimensão normativa) e para definir os principais princípios que permitem orientar a acção pública (dimensão instrumental) visando produzir o assentimento e fabricar o consenso. As sociedades de

\footnotetext{
"Isso implica o repensar de conceitos centrais da teoria sociológica tais como o conceito de poder, de "racionalidade limitada", etc. mas também a crítica a uma abordagem muito individualizante e microssociológica da decisão propondo uma contextualização muito própria da acção no seio das organizações.
} 
hoje caracterizam-se por uma grande diversidade de crenças e valores e cada pessoa ou organização apoia-se sobre uma pluralidade de representações do mundo para justificar as suas acções. As crenças forjam-se progressivamente por confronto com outras pessoas e organizações ou com outros princípios de legitimidade sendo mais o resultado da experiência do que a interiorização de um sistema de valores. No concreto das situações de interacção, as pessoas procedem a ajustamentos, constroem compromissos entre os diferentes princípios e são levadas a estabelecer uma hierarquia de preferências e de valores sopesando os seus interesses, as suas experiências e os seus princípios.

Toda a regulação de um conflito, e toda a procura de consenso, passa por um acordo prévio face a um princípio superior em nome do bem comum, ou ainda, por um princípio de equivalência que permite estabelecer uma ordem de hierarquia entre as pessoas ou os interesses (ex: ordem de hierarquias na etiqueta para servir uma refeição - por todos aceite). As pessoas agem assim sob o império das convenções que definem princípios de coexistência e as classificam. Neste contexto, os conflitos sociais mobilizam actores que lutam para se apropriar da possibilidade de dar sentido ao seu agir procurando tornar-se sujeitos da própria acção, produzindo significados próprios face às suas interpretações do mundo e aos seus interesses e face aos vários campos da vida social: dos interesses económicos, às formas de ver a vida, a sexualidade, a família, etc.

\section{E o papel do sociólogo?}

O colocar a acção colectiva no centro da profissão do sociólogo que trabalha no planeamento, obriga a re-equacionar o seu papel agora como interveniente em contextos de mudança complexos.

Há três níveis de questões de ordem metodológica que têm maior impacto nas metodologias de planeamento e qualquer delas traz "rupturas" epistemológicas com os métodos tradicionais de análise: o recurso a metodologias de investigação-acção; as metodologias que apelam à participação e as metodologias que decorrem da análise de sistema.

A investigação-acção neste contexto traz duas grandes rupturas (que estão associadas entre si) face aos métodos tradicionais. Por um lado, a passagem de uma causalidade linear a uma causalidade complexa dado que complexos são os sistemas com os quais trabalhamos e, por outro lado, o centramento na acção faz com que o objectivo fundamental seja a resolução de problemas e não a produção de conhecimento em si mesmo. Acrescente-se que num processo de investigação-acção a aferição das hipóteses realiza-se através da avaliação dos resultados da acção.

As metodologias participativas mereceriam uma maior discussão, pois são diversos os entendimentos e coexistem uma diversidade de conceitos com impactes e finalidades que não se sobrepõem, mas estão associadas sobretudo à incorporação dos actores sociais nos processos de conhecimento, acção e avaliação. Estando implícitas às metodologias de investigação-acção parece útil, no entanto, fazer a distinção entre as metodologias de produção de conhecimento e as de "animação".

As metodologias que se socorrem da análise sistémica, renovadas hoje, pelo ressurgimento das teorias (e métodos) da análise das redes trazem não apenas conceitos centrais, mesmo quando tradicionais (abertura, fechamento, regulação, energia, etc.), como utensílios práticos de análise, o mais interessante dos quais é a modelização sistémica como forma gráfica de representação dos sistemas de acção tornando o complexo inteligível.

\section{As virtualidades e os limites das novas formas de fazer sociologia}

Equacionando os novos caminhos e desafios das formas de fazer sociologia damo-nos conta que nem tudo está claro e é cientificamente satisfatório. As críticas mais frequentes aos métodos e técnicas disponíveis são:

- Confusão entre técnicas descritivas, interpretativas e de "animação";

- Técnicas pouco aferidas para as ciências sociais e culturalmente pouco adaptadas;

- Técnicas simplistas e necessitando de técnicas clássicas para as "triangular;

- Técnicas pouco amigáveis para utilização com os actores;

- Técnicas pouco reconhecidas academicamente;

- No que diz respeito à "estratégia de actores": 
- Frequente separação dos processos de conhecimento da acção;

- Transmissão de conhecimentos, e portanto, de poder para apenas um dos actores, o encomendador sem controlo.

De facto, estes novos métodos e formas de fazer são apenas uma parte dos métodos e técnicas em ciências sociais e a maioria das vezes necessitam ser "triangulados" com metodologias de trabalho tradicionais como entrevistas, questionários, etc.

Se se pode considerar que a distinção entre uma sociologia académica e uma sociologia profissional não tem qualquer espécie de sentido é, no entanto, preciso considerar que não é a mesma reflexão construir objectos para o conhecimento e construí-los para a intervenção: não tem o mesmo tipo de equacionamento da problemática, não se utiliza da mesma forma o controlo de método. Estas diferenças são importantes e precisam ser discutidas porque é preciso que a academia consiga manter com identidade e valor os dois tipos de trabalho. É arriscado confundir os registos porque exactamente o campo da pesquisa académica é um campo muito mais alargado que coloca problemas de uma amplitude que não se colocam ao nível da pesquisa-acção tal como é necessária ao planeamento onde trabalhamos sobretudo com teorias intermédias de médio alcance.

No planeamento, uma parte significativa das discussões sobre as novas metodologias de traba-

\section{Bibliografia}

BRATOSIN, Stefan, 2001, La concertation: forme symbolique de l'action collective, Paris, Harmattan.

CEFAI, Daniel e TROM, Danny, 2001, Les formes de l'action collective: mobilisations dans des arènes publiques, Paris, École des Hautes Études en Sciences Sociales.

DROUART, Hervé, LEGROS, Michel, PASCAL, HENRI, 1991, Sociologie e Intervention sociale: manuel de sociologie génerale, Paris, Centurion.

HERREROS, Gilles, 2002, Pour une sociologie d'intervention, Paris, Érès. lho são mais questões de ordem ética e política do que de ordem científica ou técnica. Trabalhar com actores, partilhar conhecimentos e saberes e, sobretudo, gerir "encomendas sociológicas" com actores públicos que têm de dar visibilidade ao seu investimento, gera contradições e exige compromissos de ordem ideológica nem sempre simples. O técnico tem de saber definir os seus pressupostos e princípios e torná-los transparentes face ao conjunto dos actores, ao mesmo tempo que clarifica os limites dos seus compromissos com os actores nomeadamente com o encomendador.

As capacidades de argumentação, de adequação da linguagem e a pedagogia da reflexividade são importantes, assentes na noção de que o nosso papel não é apenas produzir conhecimento é também socializá-lo. Aos actores não lhes compete serem cientistas sociais, mas é ao sociólogo que compete ser capaz de interagir com o político, com o técnico, com o representante da população, etc.

Finalmente, as técnicas de que hoje dispomos são pouco aferidas por nós. As técnicas de planeamento vamos buscá-las à gestão fundamentalmente, concebidas para contextos bastante diferentes daqueles que temos, e nem sempre estão bem organizadas e adaptadas ao trabalho social. Sobretudo as técnicas americanas têm um contexto cultural muito diferente do português. A necessidade de adaptação dos instrumentos de trabalho e a aferição para os campos específicos de trabalho exigem um esforço (e um tempo) considerável.

MELUCCI, Albert, 2001, A invenção do presente: movimentos sociais nas sociedades complexas, Brasil, ed. Vozes.

OUELLET, Christine, SAINT-Jacques, Marie-Christine, TURCOTTE, Daniel e colaboradores, 2000, Méthodes de Recherche en Intervention Sociale, Canadá, Gaetan Morin Editeur.

SOUSA SANTOS, Boa Ventura (org.), 2003, Democratizar a democracia: os caminhos da democracia participativa, Porto, Edições Afrontamento.

GUERRA, Isabel, 2003, "Polémicas e Modelos para uma Sociologia de Intervenção", Caderno de Estudos Africanos, $\mathrm{n}^{\circ} 4$, Cascais, Principia, pp. 71-84. 